\title{
CORRESPONCENCE
}

\section{The Treatment of Climacteric Symptoms}

by Prof. Dr. med. Olaf Ortmann, Dr. med. Claus Lattrich in volume 17/2012

\section{Do Not Forget Estrogen Therapy}

The absolute numbers for the prevalence rates for osteoporosis and other sequelae of estrogen deficiency were not reported in the article. Osteoporosis affects one in every three women. More than 100000 women contract fractures of the neck of femur every year, and $10-20 \%$ die as a result in the aftermath. In 55000 incident cases of breast cancer, cure is possible in $85 \%$, and a higher incidence of breast cancer owing to hormone replacement has been disproved or, in the worst-case scenario, is about one in 1000. The WHI (Women's Health Initiative) Study, the largest on the subject, showed that the risk of breast cancer was significantly reduced in women taking estrogen replacement therapy-namely, by $20 \%$. German data show that women who take HRT have a $30 \%$ lower risk of being admitted as inpatients to be treated for breast cancer. A US study showed that the risk of stroke was $0.1 / 10000$ women aged 50-60 (1). In Germany, osteoporosis related fractures cost some 3 billion euro every year. The total costs for osteoporosis amount to 6 billion euro. Women aged 47 or younger at menopause have double the risk of osteoporosis as do women with a later menopause: after 34 years of observation, 56-30\% (fractures within the respective groups: $44 \%$ to $31 \%$ ) (2) Furthermore, mortality in women with an earlier menopause was $52-35 \%$ higher. This was confirmed by large metaanalyses $(n=26000)(4)$ : more than $40 \%$ reduction in mortality in women taking hormone therapy than in women with a later menopause. A study in Californian teachers showed a 50\% reduced risk for coronary cardiovascular diseases and $50 \%$ reduction in overall mortality for HR ( $\mathrm{n}=71000)$. By contrast, the risks associated with hormone replacement are 0.6-0.2/1000. Twice as many women die from the consequences of osteoporotic fractures than from breast cancer.

DOl: 10.3238/arztebl.2012.0714a

\section{REFERENCES}

1. Lobo RA: The risk of stroke in postmenopausal women receiving hormonal therapy. Climacteric 2009; 12: (Suppl 1) 81-5.

2. Svejme 0 , et al.: Early menopause and risk of osteoporosis, fracture and mortality: 34-year prospective observation study in 390 women. BJOG 2012; DOI: 10.1111/j.1471-0528.2012.03324x.

3. Salpeter SR, et al.: Mortality associated with HRT in younger and older women. J Gen Intern Med 2004; 19: 701-804.

4. Ortmann 0 , Lattrich C: The treatment of climacteric symptoms. Dtsch Arztebl Int 2012; 109(17): 316-24.

Prof. Dr. med. Dipl. Psych. J. Matthias Wenderlein

Universität Ulm, wenderlein@gmx.de

\section{In Reply:}

It is entirely correct to say that osteoporosis is one of the health risks in women after the menopause and should therefore be treated. It is rare in perimenopausal women and does not cause the classic problems associated with the climacteric (vasomotor complaints, vaginal atrophy). Treating these problems was the main focus of our article. Several methods are available to treat osteoporosis (see "AWMF S3-Leitlinie Prophylaxe, Diagnostik und Therapie der Osteoporose bei Frauen ab der Menopause, bei Männern ab dem 60. Lebensjahr" [S3 guideline on the prophylaxis, diagnostic evaluation and therapy of osteoporosis in postmenopausal women and men aged 60 or older]), so that hormone therapy with estrogens for the treatment of osteoporosis can be recommended only where these methods are contraindicated. The most recent evaluation of the WHI study showed that after a mean follow-up of 11.8 years, the incidence of breast cancer is lowered for a mean duration of monotherapy with estrogen (ET) of 5.9 years (hazard ratio $0.77,95 \%$ confidence interval 0.62 to $0.95, \mathrm{P}=0.02$ ) (1). The Million Women Study, however, found an increase in the incidence of breast cancer resultant to ET, so that the real situation cannot be evaluated conclusively from the existing data (2). ET can be given only to women who have had hysterectomies; in most women, combined estrogen-gestagen therapy is required, which leads to an increase in the risk of breast cancer after long-term use ( $>3-5$ years) $(3)$.

DOI: 10.3238/arztebl.2012.0714b

\section{REFERENCES}

1. Anderson GL, Chlebowski RT, Aragaki AK, et al.: Conjugated equine oestrogen and breast cancer incidence and mortality in postmenopausal women with hysterectomy: extended follow-up of the Women's Health Initiative randomised placebo-controlled trial. Lancet Oncol 2012; 13: 476-86. Epub 2012 Mar 7.

2. Beral V, Reeves G, Bull D, Green J; Million Women Study Collaborators: Breast cancer risk in relation to the interval between menopause and starting hormone therapy. J Natl Cancer Inst 2011; 103 : 296-305. Epub 2011 Jan 28.

3. The 2012 Hormone Therapy Position Statement of The North American Menopause Society: Menopause 2012; 19: 257-71.

4. Ortmann 0, Lattrich C: The treatment of climacteric symptoms. Dtsch Arztebl Int 2012; 109(17): 316-24.

Prof. Dr. med. Olaf Ortmann, Dr. med. Claus Lattrich

Klinik für Frauenheilkunde und Geburtshilfe

Universitätsklinikum Regensburg

am Caritas-Krankenhaus St. Josef

olaf.ortmann@klinik.uni-regensburg.de

\section{Conflict of interest statement}

Professor Ortmann has received honoraria for acting as an expert adviser from Dr Wolff Pharma and research support from Medinova. Dr Lattrich declares that no conflict of interest exists. 